IRA-International Journal of Applied Sciences ISSN 2455-4499; Vol.04, Issue 01 (2016)

Institute of Research Advances

http://research-advances.org/index.php/IRAJAS

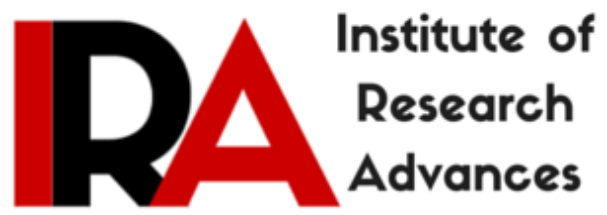

\title{
Epidemiology of Cracker (Fire Works) Injuries in a Tertiary Burn Care Centre
}

\author{
${ }^{1}$ Dr. B. Rajeswari, M.S., M.Ch., Assistant Professor \\ ${ }^{2}$ Dr. B. Shankari, M.S., M.Ch., Assistant Professor \\ ${ }^{3}$ Dr. Angeline Selvaraj, M.S., M.Ch., Professor \\ ${ }^{\mathbf{1}, 2,3}$ Department of Burns, Plastic and Reconstructive Surgery, \\ Govt. Kilpauk Medical College, Chennai - 6000 10. India.
}

DOI: http://dx.doi.org/10.21013/jas.v4.n1.p2

\section{How to cite this paper:}

Rajeswari, B., Shankari, B., \& Selvaraj, A. (2016). Epidemiology of Cracker (Fire Works) Injuries in a Tertiary Burn Care Centre. IRA-International Journal of Applied Sciences (ISSN 2455-4499), 4(1). doi:http://dx.doi.org/10.21013/jas.v4.n1.p2

(C) Institute of Research Advances

\section{(c)) EY-NC}

This works is licensed under a Creative Commons Attribution-Non Commercial 4.0 International License subject to proper citation to the publication source of the work.

Disclaimer: The scholarly papers as reviewed and published by the Institute of Research Advances (IRA) are the views and opinions of their respective authors and are not the views or opinions of the IRA. The IRA disclaims of any harm or loss caused due to the published content to any party. 


\section{ABSTRACT}

Fireworks related burns are one of the causes of recurring incidences of burn injuries every year during festivals. Sporadic events are reported in family and communal celebrations / temple festivals and in funerals. These burns are different from other burns as the burn percentage is not the major burden, but the increasing number of patients with cracker burn injuries with loss of hand function, loss of vision and at times blast injury of the face with major tissue loss and multiple fractures (shattered tissues), which are challenging for the reconstructive surgeon, are major concern. The vulnerable groups are innocent children who sustain injuries due to ignorance, negligence and lack of supervision. These fire cracker burn wounds are to be classified separately as the wounds are more like traumatic wounds than burn wounds. They are also associated with more morbidity than mortality. ${ }^{(1,2,3)}$

The management of these wound is multidisciplinary, with involvement of various specialists like paediatricians, ophthalmologists, psychiatrists, orthopaedic surgeons and specialists in rehabilitative medicine along with plastic and reconstructive surgeons. Reconstruction of blast hand and face needs multiple surgeries and prolonged period of physiotherapy and rehabilitation. The effective and appropriate decision made in the acute phase is important to reduce their morbidity. ${ }^{(4)}$

Keywords: Firework injuries, cracker burns, cracker blast hand, cracker blast of face.

\section{INTRODUCTION}

Fire cracker injuries occur commonly during religious festivals, family or communal celebrations in our country (INDIA). It causes various types of burn wounds and blast injuries involving different parts of the body. It commonly involves face and hand which may lead to total or partial loss of hand with its function / Loss of vision. Facial blasts are rare, and most of the time fatal, and tough to manage due to major tissue loss. They are potentially preventable. To create awareness about safety measures by mass education, legislation, and standardisation of manufacture can go a long way in prevention of such incidents. It needs continuous effort of health care systems. The purpose of this study is to analyse the various types of fire cracker related wounds. This would be a first step in creating awareness among healthcare personnel. By motivating them, it is hoped that awareness will be transmitted to the vulnerable groups.

\section{TYPES OF CRACKER CAUSING INJURY: ${ }^{(5)}$}

Among the commonly used crackers, flower pot causes majority of burn wounds. The unburned flower pots, which burst at the second attempt of lighting the cracker is the main cause of hand burns and blasts.

Children play with the cracker powder, the chemical packed inside the crackers. They peel crackers and the powder is collected in a paper and lighted. Blowing into the fire for inducing fire glow causes burns over face, as face is closer to the fire. While doing so even the bystanders sustain injuries. The blasts are generally avoided by the sudden, reflex with drawl away from the fire. The facial blasts may happen due to unexpected explosion of the flower pot cracker, due to faulty manufacturing and poor quality.

\section{MECHANISM OF FIRECRACKER INJURIES ${ }^{(6,7,8)}$}

\section{Heat}

The heat produced from ignited fire crackers may exceed $650^{\circ} \mathrm{C}$. This rise in temperature cause burns on the exposed parts of the body. The parts of the body commonly subjected to burn injuries are the face, hands and feet. 


\section{Blast}

Because of sudden displacement of air, there may be an increase in pressure causing blast effect. This pressure of the blast may cause injuries to the different parts of the body, by varying mechanisms.

Hand : ${ }^{(9)}$

The pressure built up by blast passes through the tissues of least resistance in hand ie., through the inter osseous, musculo-tendinous soft tissue compartment and disrupts the tissues leaving the bone bare. Aim in reconstruction of such injuries of the hand should not only be in restoring anatomical continuity of structures, but also in obtaining good functional results. Major efforts are required to reconstruct the anatomy and to rehabilitate the hand.

Vision: ${ }^{(10,11,12)}$

Normally the eyes are protected by the reflex closure of eyelids. It may cause burns of lids alone. In cases of blasts there may be loss of eye due to rupture of globe. This is due to pressure distribution through the path of least resistance. There may be associated fracture of facial bones which needs major effort at reconstruction. When vision is lost, it cannot be restored by any modality. Reconstruction is done, only for cosmetic purpose and to create socket for artificial eye.

For ease of management, we have used this clinical classification for fire crackers burn wound:

Group I: Hand burns

Group II: Hand blasts

Group III: Facial burns

Group IV: Facial blast

Group V: Combined flame and blast of any part of the body.
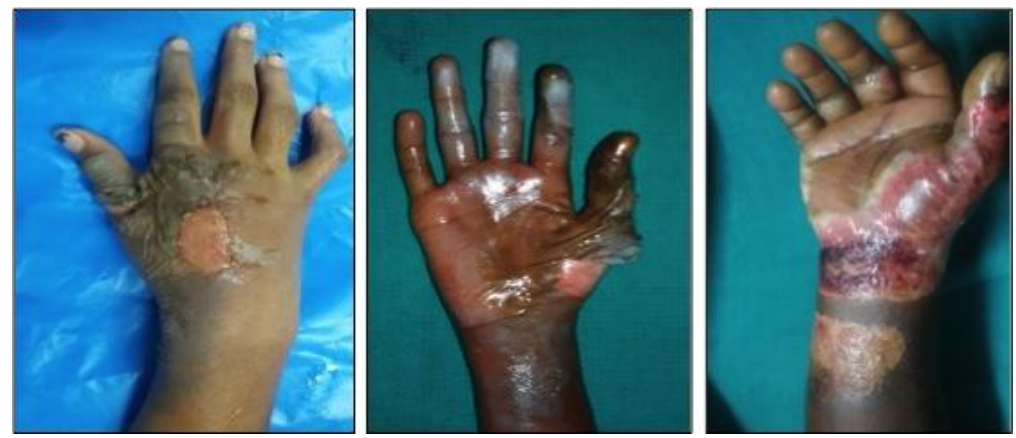

Group I: Hand burns 

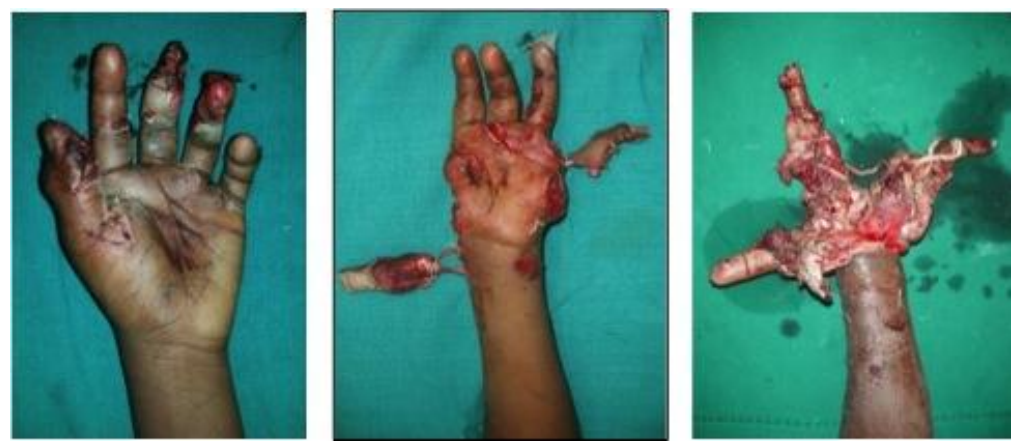

Group II: Hand blasts
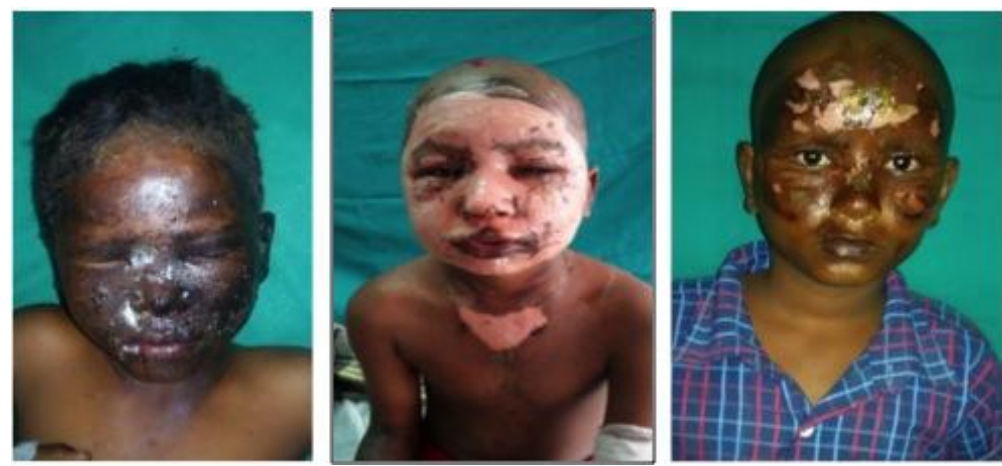

Group III: Facial burns

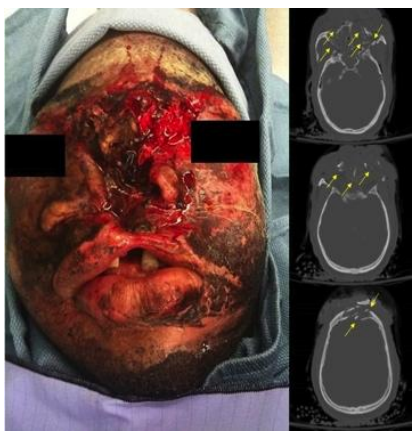

Group IV: Facial blasts

Group V: Combined flame and blast of any part of the body

\section{AIM}

Our aim is to study the incidence of cracker related burns, prevalence, age and sex preponderance, type of cracker involved, type and severity of the injury with associated morbidity and mortality, management of wound, effective preventive methods and future planning.

\section{MATERIALS AND METHODS}

STUDY GROUP: Patients admitted with burns due to crackers in the Department of Burns, Plastic and Reconstructive surgery, Government Kilpauk Medical College and Hospital, Chennai, India. 
STUDY DESIGN: Retrospective study

STUDY PERIOD: The study period was from Jan 2013 to Dec 2015(36 months).

METHODOLOGY: Data collected from number of patients treated with cracker induced burns during festivals and non festival sporadic events were analyzed for epidemiological study regarding the incidence, prevalence, age and sex preponderance, type of cracker involved, type and severity of injury, associated morbidity and mortality, management of wound, effective preventive methods, and future planning.

INCLUSION CRITERIA: All burns related to crackers (while handling / setting fire) during festivals and other events.

EXCLUSION CRITERIA: Accidents at manufacturing sites / at sales counter

\section{ADMISSION CRITERIA:}

- All cracker burn cases involving the face.

- All blasts due to fire crackers

- All paediatric cases with fire cracker burns of any percentage

- Adult hand burns with excessive edema / stiff painful hand.

MANAGEMENT PROTOCOL ${ }^{(13,14)}$

\section{FLUID RESUSCITATION:}

As the TBSA of burn wound is usually a smaller percentage and fluid management is not a major issue. Patients are managed with maintenance IV fluids, and normal diet.

\section{NUITRITION:}

Protein rich diet was prescribed for all the patients. Vitamin $\mathrm{C}$ enriched fruits and iron containing foods recommended with multi vitamin and zinc supplements. Formula diet was not used.

\section{PAIN RELIEF:}

Pain management has a major role in hand burns and blasts. Blast injury of hand and eyes causes excruciating pain due to edema, disruption of tissues (tearing), bone fractures and exposure of sensory nerves. It was managed with parenteral analgesics, anti-inflammatory drugs, and sedatives. Strict hand and head end elevation played an important role in relieving pain and swelling. Steroids were also commonly used for facial burns to decrease edema, and thereby indirectly, to relieve pain.

IV. WOUND CARE: ${ }^{(15,16)}$

A. INFECTION CONTROL: Antibiotics were started on admission according to the previous month's ward swab culture report. There after it was changed according to the wound culture report which was done periodically on the patient's wounds.

B. COLLAGEN APPLICATION: Most of the time, the hand and facial burn wounds (Groups I and III) were managed conservatively with closed dressings. Closed dressings were done after application of silver sulphadiazine cream liberally over the wounds and covering with pads and bandages. Eyes specially protected by keeping saline pads with periodical instillation of protective antibiotic and artificial tear drops as prescribed by ophthalmologists. When the hand burns were superficial second degree, and 
were not circumferential, was covered with collagen. Most of the facial burn patients were managed conservatively.

C. WOUND DEBRIDEMENT: Blasts of hand were treated by early wound debridement to give immediate flap cover, to achieve maximum functional outcome. If wound bed was not satisfactory at the first time, managed with watchful expectancy till it got ready for flap cover. Emergency amputations of digits were done in some cases. There was no need for fasciotomy for the blast hand as there was shattered tissues with open tissue planes.

\section{MANAGEMENT OF OCULAR INJURIES AND FACE BLASTS ${ }^{(17,18)}$}

There were no cases of face blasts during this period of study. But in literature lot of cracker related facial blasts have been reported, which usually are fatal due to massive haemorrhage and upper air way injury. The survivors need multiple surgeries for managing fracture and gross disfigurement of face. We had two patients of ocular injury. One patient had rupture of globe with loss of vision in one eye and corneal burns in the other with partial loss of vision. Other patient had corneal and conjunctival burns of both eyes, with partial loss of vision in both eyes. They were referred to the ophthalmic surgeons in Regional Ophthalmic Institute for management. They didn't turn up for follow up.

\section{RECONSTRUCTION}

Various reconstructive methods were adapted depending upon the wound status to regain maximum form and function.

1. Wound debridement and primary closure. (Fig:1)

2. Shortening and closure for finger injuries with tissue and bone loss. (Fig:2)

3. Skin grafting for superficial wounds.(Fig:3)

4. Flap cover: Abdominal and groin flap cover were given, depending upon the size and site of soft tissue defect.(Fig:4)
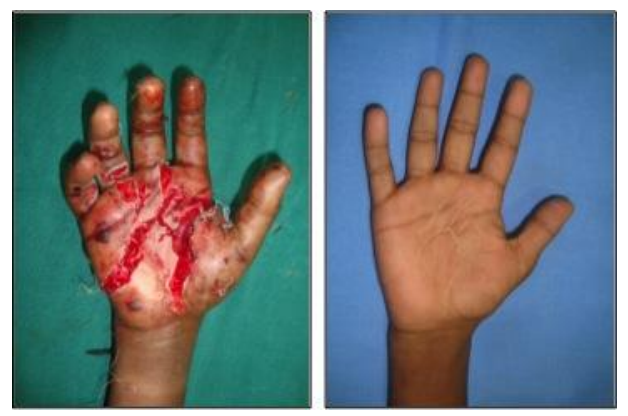

Fig 1: Primary skin suturing of cracker burst wound on the hand 

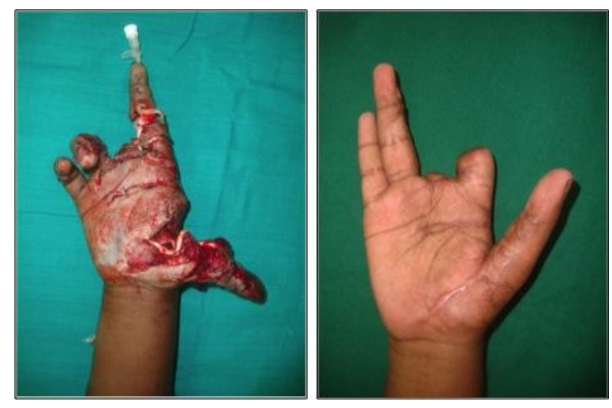

Fig 2: Shortening and closure of gangrenous fingers and stumps, following cracker blast injury
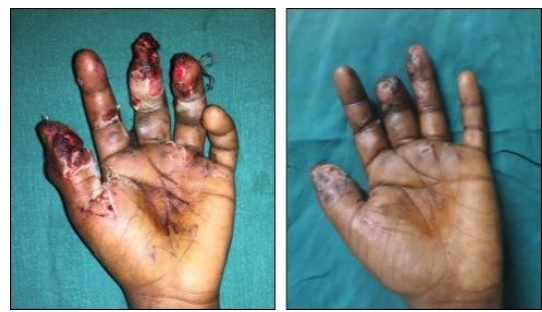

Fig 3: Skin grafting of thumb wound following cracker blast injury
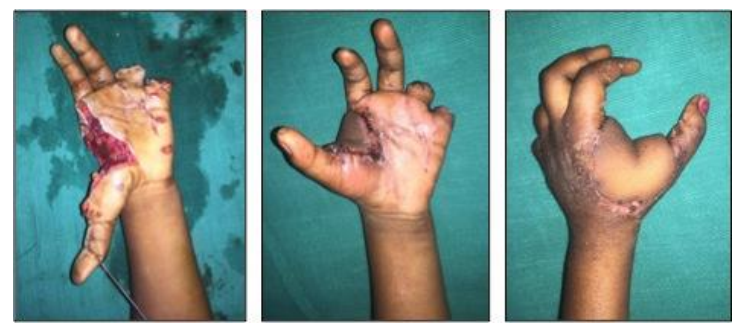

Fig 4: Groin flap to restore thumb web in a cracker blast injury

\section{PHYSIOTHERAPY /REHABILITATION: ${ }^{19}$}

Effective physiotherapy was started early in the acute phase itself, with splinting, followed by active and passive finger and wrist exercises. Frequent eye opening and tight closure of lids was advised to avoid frozen lids, and exposure keratitis. Physiotherapy was continued for a long time in case of hands to regain maximum functional outcome.

\section{OUR STUDY REPORTS}

INCIDENCE: There were 213 patients treated for cracker burn and blast injuries in the period from January 2013 to December 2015. 


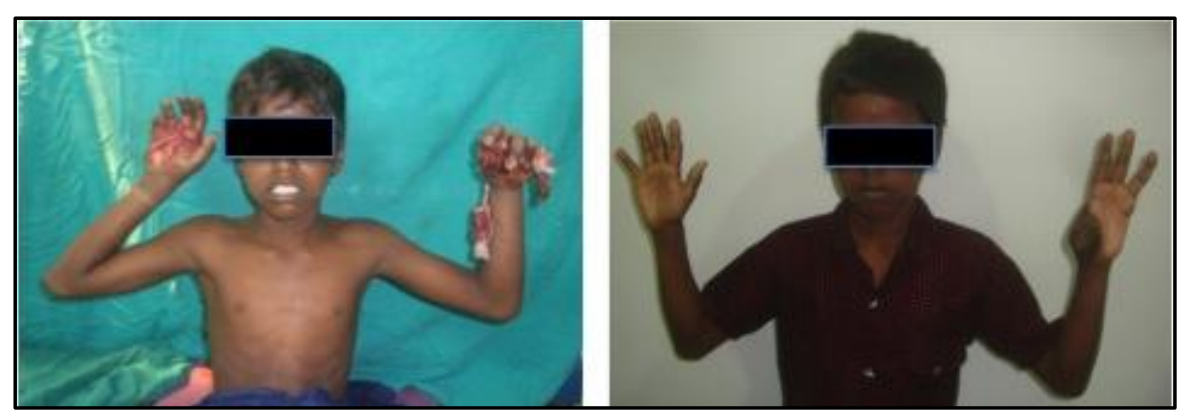

Fig 5: A patient with a bilateral hand blast injury

The number of patients who needed admission were 48 and the number of patients treated as out-patient were 165 .

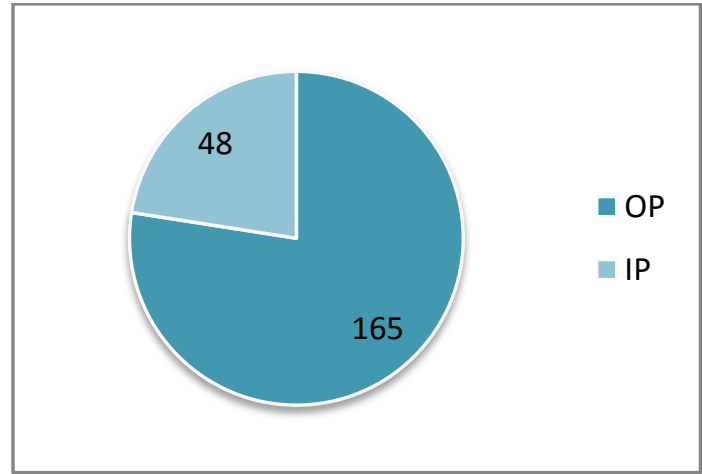

Chart 1: Relationship between number of OP cases and IP cases treated for cracker burn and blast injuries

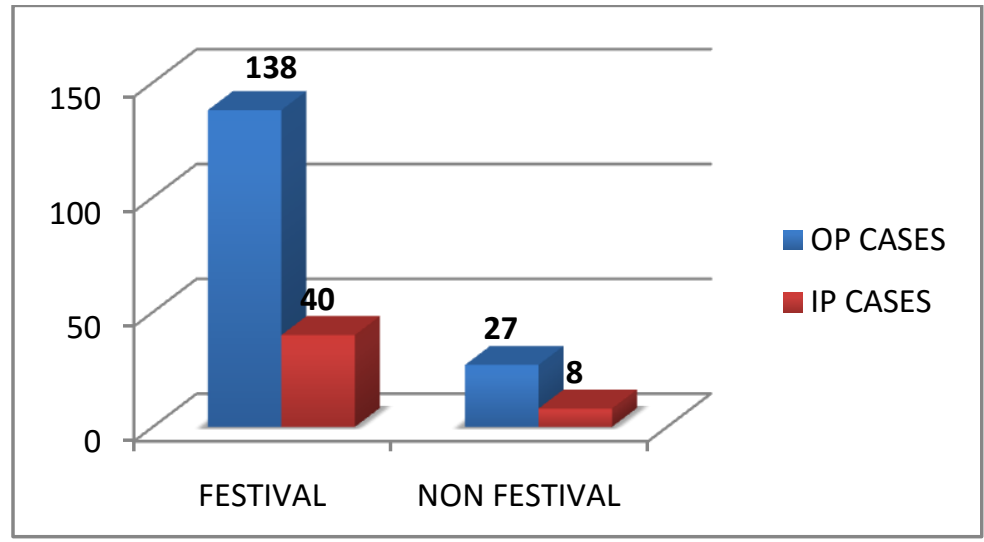

Chart 2: Comparison of incidence of cracker injuries during festival and non-festival seasons.

The incidence was found to be more common in and around festival seasons. 


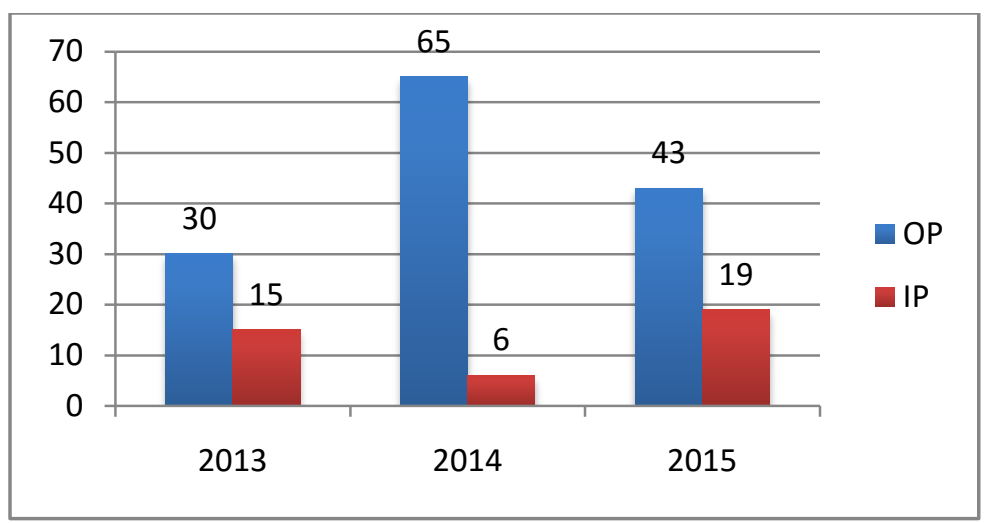

Chart 3: Breakup of cracker burn injuries during the festival season over a period of 3 years.

[We had Cracker burn incidences usually during Diwali, Karthigai Deepam and New Year]

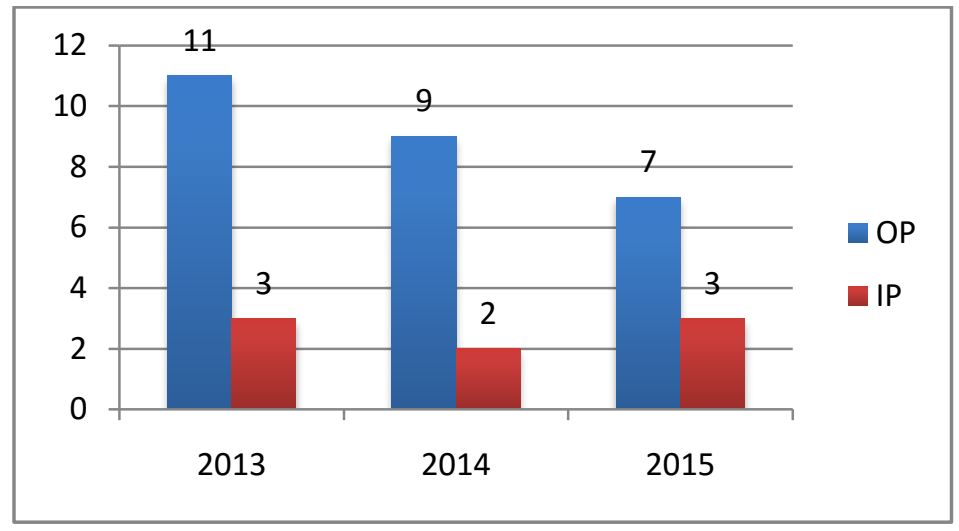

Chart 4: Distribution of cracker burns during non-festival incidences over 3 year

\section{AGE AND SEX PREPONDERANCE:}

AGE:

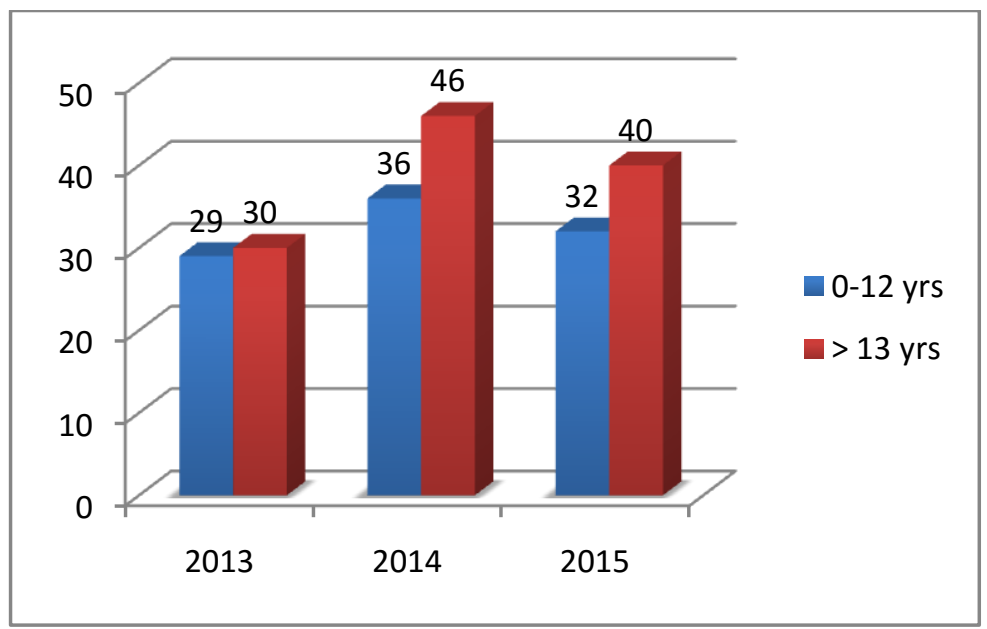

Chart 5: Distribution of cracker burns by age. [The most affected groups were between 13 and 20 years of age. The second common age group for cracker burn injuries was the age group less than 13years] 
SEX:

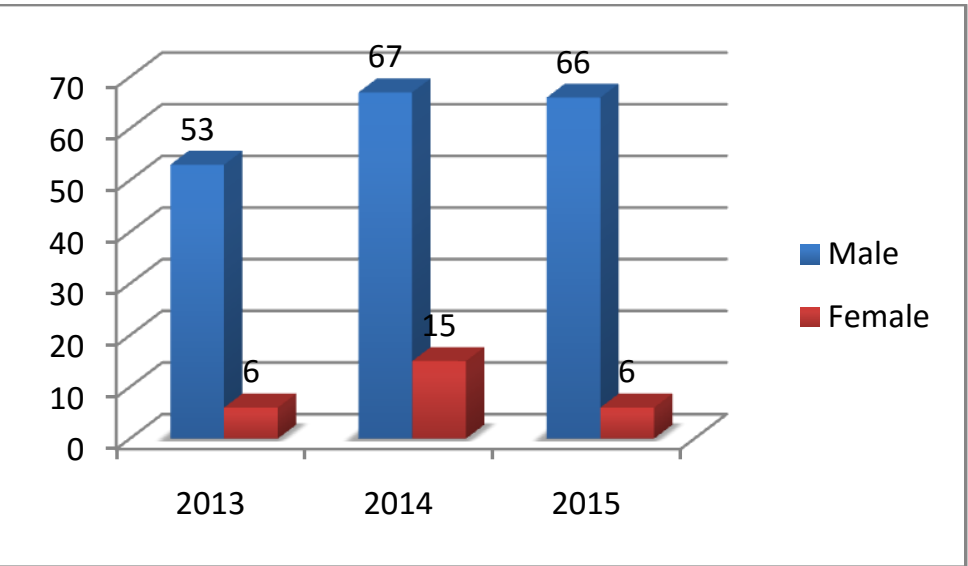

Chart 6: Sex distribution of cracker burn injuries. There was a marked male preponderance.

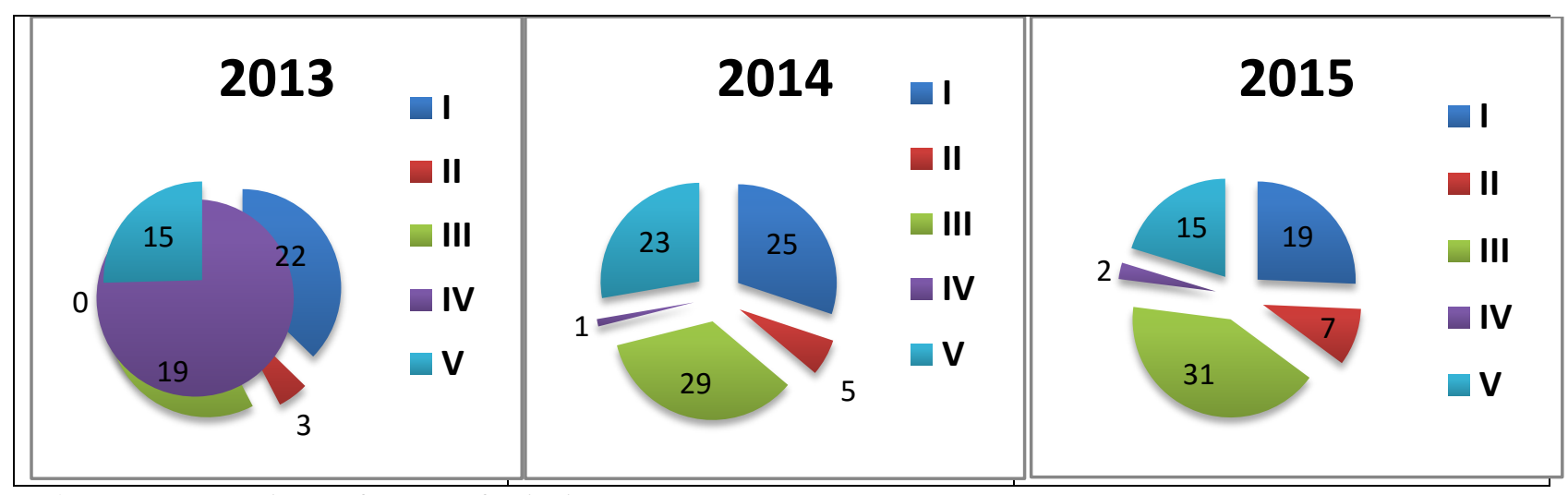

Chart 7: Comparison of types of Injuries over 3 years

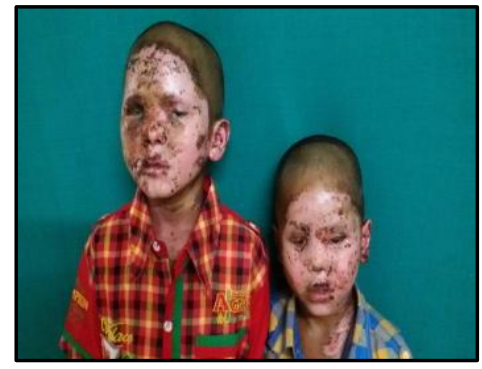

Fig 6: Two boys with face burn injuries (Group III)

(They are brothers. Mode of injury was due to cracker powder. One lost vision in one eye)

\begin{tabular}{|c|c|c|c|}
\hline Eyes & $60(28 \%)$ & & \\
\hline Face & $52(24 \%)$ & & (o) \\
\hline Hand & $142(66 \%)$ & & $\begin{array}{l}\text { Arms } \\
9(4 \%)\end{array}$ \\
\hline Legs & $20(9 \%)$ & & Hand \\
\hline
\end{tabular}




\begin{tabular}{|l|l|l|}
\hline Trunk & $29(13 \%)$ & \\
\cline { 1 - 2 } Arms & $9(4 \%)$ & \\
\hline
\end{tabular}

Chart 8: Distribution of injuries caused by crackers in the body.

\section{TREATMENT OUTCOME:}

With hand and facial burns ,despite conservative management, outcome was good. Blasts of hand required multiple surgical attempts to restore the anatomical continuity. Though anatomical restoration was satisfactory, functional recovery was not satisfactory

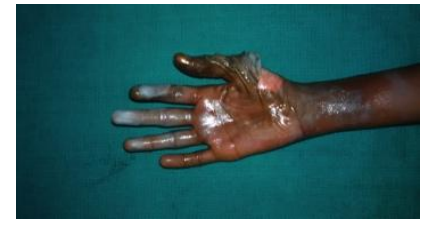

Acute burn hand

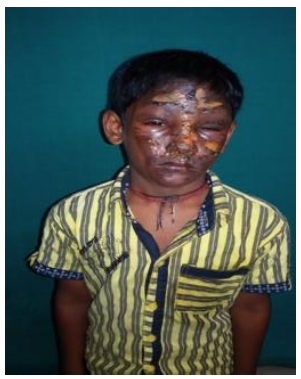

Acute burn face

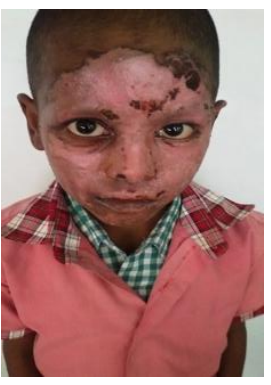

After healing

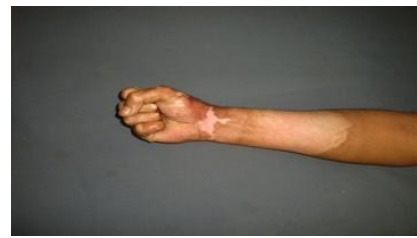

After healing

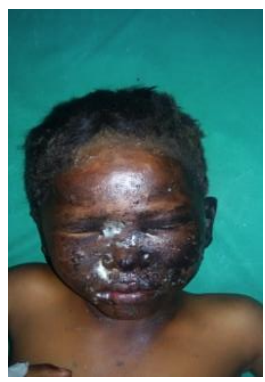

Acute burn face

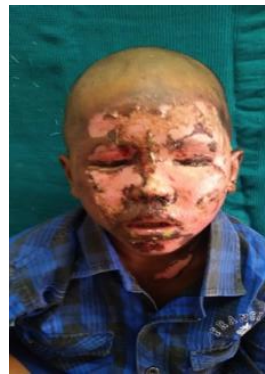

After healing
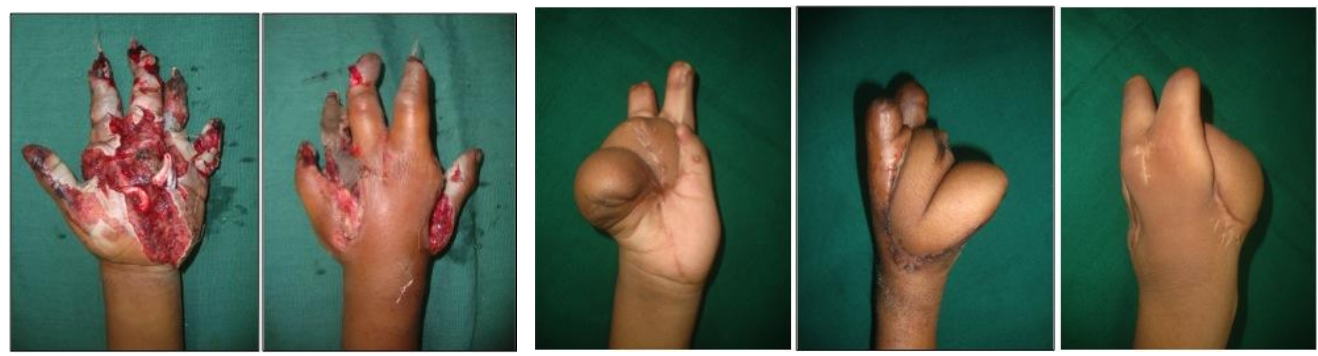

Fig 7: Reconstruction after a major blast injury of hand

\section{PREVENTION: ${ }^{(20)}$}

We conduct school health program to create awareness about the causes and complications of fire cracker, a month ahead of festival time every year. Our social workers distribute pamphlets carrying information on safety precautions, and first aid measures, to the public in bus stands, public gatherings, shops, and railway stations. College students are motivated to get involve in passing on the health care information. 


\section{DISCUSSION}

Fire cracker burns, are the burns that cause more morbidity and affect younger generation. The cumulative incidences in the long run definitely have considerable amount of physical disability. Our study is to highlight the fact that it is preventable, by education and by strict implementation of law.

\section{CONCLUSION}

These wounds are more like traumatic wounds rather than burn wounds. It can be classified separately into 5 groups. Though reconstruction procedures were done, the functional results in blast injury groups were not encouraging. Hence, prevention of such major devastating injuries must be the goal.

Caution must be exercised in bursting firecrackers. Awareness must be improved among all sections of society and all age groups.

Our institutional study is only the tip of the Ice berg. Fire work burns has to be considered as major health hazard. It is definitely preventable and can be minimized if the WHO's criteria for prevention is followed strictly by implementation of three E's ${ }^{21}$

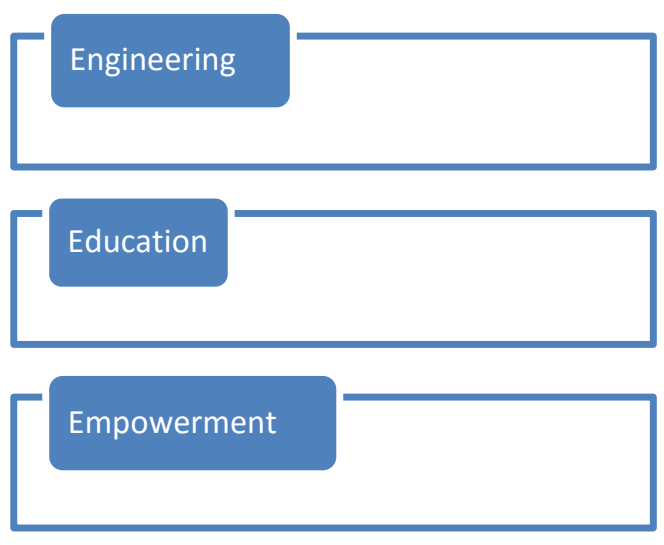

Prevention of three major disabilities -functional, cosmetic and social (emotional), by continuous effort of the entire health care system by enhancing the awareness of safety norms and strict implementation of law by the Government about standard of manufacturing, sale, and handling will definitely decrease the number of burn incidences due to firecrackers.

\section{REFERENCES}

1.Morell T., Lohmann M., Basse P.M.: "Injuries due to fireworks".Ugeskr-Laeger, Denmark, 1992.

2.McCauley R.L., Steberg B.A., Rutan R.L., Hegger J.P., Herndon D.N.: Class C firework injuries in a paediatric population. J. Trauma, 1991.

3.Udesen A., Ovesen O.C.: "Burn injuries due to fireworks during New Year Holiday. 10 year case load." Ugeskr-Laeger, Denmark, 1991.

4. Emergency management of paediatric burns. Paediatric emergency care 2005; 21:118-29.

5. United States Consumer Product Safety Commission, 2011 Annual Fireworks Annual Report: Fireworks-Related Deaths, Emergency Department-Treated Injuries, and Enforcement Activities During 2011. 
6. Puri V, Mahendru S, Rana R, et al. Firework Injuries: a ten-year study. JPARS. 2009;62:11031111.[PubMed]

7. Peng CZ, How CK, Wang CY, et al. Unusual Penetrating Preauricular Injury by Firework Rocket. Intern Emerg Med. 2012;7:85-86. [PubMed]

8. Wang C, Zhao R, Du WL, et al. Firework injuries at a major trauma and burn center: A five-year prospective study. Burns. 2013 pii: S0305-4179(13)00189-7. [PubMed]

9.Kon N.: Firework injuries to the hand. Ann. Chir. Mains MembSup6r., France, 1991.

10. Morley MG, Nguyen JK, Heier JS, et al. Blast eye injuries: a review for first responders. Disaster Med Public Health Prep. 2010;4(2):154-60. [PubMed]

11. Malik A, Bhala S, Arya SK, et al. Five-year study of ocular injuries due to fireworks in India. Int Ophthalmol. 2013 Jan 13; [Epub ahead of print] [PubMed]

12. Cockerham GC, Rice TA, Hewes EH, et al. Closed-eye ocular injuries in the Iraq and Afghanistan wars. N Engl J Med. 2011 Jun 2;364(22):2172-2173. [PubMed]

13. Wallace A B; Treatment of Burns, Ann.R.Coll.surg, 1949;5:28.

14. TOTAL BURN CARE -Third edition -David N .Herndon MD, FACS page: 485-501.

15. Abubaker AO. Use of prophylactic antibiotics in preventing infection of traumatic injuries. Oral Maxillofac Surg Clin North Am. 2009;21(2):259-64. vii. [PubMed]

16. Adalarasan S, Mohan A, Pasupathy S. Prophylactic antibiotics in maxillofacial fractures: a requisite? J Craniofac Surg. 2010 Jul;21(4):1009-1011. [PubMed]

17. Wisse RP, Bijlsma WR, Stilma JS. Ocular Firework Trauma: A Systematic Review On Incidence, Severity, Outcome and Prevention. Br J Ophthalmol. 2010;94:1586-1591. [PubMed]

18. Abdulwadud O, Ozane-Smith J. Injuries associated with fireworks in Victoria: an epidemiological overview. Injury Presentation. 1998;4:272-275. [PMC free article] [PubMed]

19. Kwan. M, Kennis. W: Splinting programme for patients with Burned Hand .Hand surgery,2002;7(2);231-241.

2O. Saadat S, Mafi M, Smith GA. Higher education does not protect against firework-related injuries: a review of the economic burden and the risk factors of firework-related injuries in the capital of Iran. Public Health. 2012;126(1):40-46. [PubMed]

21. Burn success stories / lessons learned WHO 2011 Etienne Krug, MD, MPH, Department of violence and Injury prevention and disability, WHO, Geneva. 